concentrations is important as hypoalbuminaemia is common in malignancy and if present will mean that the total serum calcium concentration underestimates the severity of the hypercalcaemia. If the patient is known to have a malignancy the hypercalcaemia will not usually require further investigation. In patients found to be hypercalcaemic who have a history of malignancy investigation is essential before recurrence of the malignancy is assumed. The new assays for parathyroid hormone almost invariably show low or low normal serum concentrations in malignancy whereas in hyperparathyroidism these are usually increased. ${ }^{18}$

Hypercalcaemia may be severe and life threatening and associated with appreciable symptoms or mild to moderate, commonly without symptoms. Each requires different treatment. Severe, life threatening hypercalcaemia should be diagnosed not only from the serum concentration of calcium (which will usually be above $3.5 \mathrm{mmol} / \mathrm{l}$ ) but also from the clinical features. Not all patients with severe hypercalcaemia should be treated. The decision to treat will depend on the recent quality of life, current symptoms, and the prospect of further treatment of the malignancy. Once a decision to treat has been made rapid correction of the hypercalcaemia over hours should be avoided as it seems to be dangerous.

The object of treatment is to correct dehydration, which often causes an appreciable improvement on its own, and to prescribe a drug that will have a high chance of bringing the serum calcium concentration to normal or near normal values within 24-48 hours afterwards. Although corticosteriods and calcitonin remain the most commonly used drugs, there is little published evidence to support their use. Except in some haematological malignancies corticosteroids are ineffective, ${ }^{19} 20$ and calcitonin has only a modest early effect in some patients. ${ }^{21}$ Current evidence overwhelmingly supports using an intravenous bisphosphonate drug (previously termed diphosphonate), of which only one, disodium etidronate, is currently licensed for use in hypercalcaemia.

For this reason the policy I have used for treating severe hypercalcaemia of malignancy is to give 2-3 litres of intravenous fluids each day with potassium supplements combined with daily infusions of disodium etidronate $7.5 \mathrm{mg} / \mathrm{g} /$ day for three days. ${ }^{22}$ Such a regimen is simple and almost always effective. Once the hypercalcaemia has been controlled much will depend on whether any effective treatment may be given to control the malignant process. Without such treatment hypercalcaemia often recurs within weeks.

An oral treatment that could be given to outpatients would be highly desirable for treating those with mild to moderate hypercalcaemia of malignancy, but unfortunately this is not available. Oral phosphate is effective in most patients but is tolerated by only a few; oral glucocorticoids are tolerated but are effective in only about a third of patients. ${ }^{23}$ Prostaglandin synthetase inhibitors are ineffective, as is cellulose phosphate. The only oral bisphosphonate available for prescription (disodium etidronate) does not seem to be effective; other oral bisphosphonates that are effective but not currently available are likely to be the best treatment in the future.

D A HEATH

Reader in Medicine,

Department of Medicine,

Queen Elizabeth Hospital,

Birmingham B15 2TH

1 Fisken RA, Heath DA, Bold AM. Hypercalcaemia - A hospital survey. $Q \mathcal{f}$ Med 1980;49:405-18.

2 Fisken RA, Heath DA, Somers S, Bold AM. Hypercalcaemia in hospital patients. Clinical and diagnostic aspects. Lancet 1981;i:202-7.

3 Heath DA. Hypercalcaemia and malignancy. Ann Clin Biochem 1976;13:555-60.

4 Suva LJ, Winslow GA, Wettenhall REH, et al. A parathyroid hormone-related protein implicated in malignant hypercalcemia: cloning and expression. Science 1987;237:893-6.

5 Mangin M, Webb AC, Dreyer BE, et al. Identification of a cDNA encoding a parathyroid hormonelike peptide from a human tumor associated with humoral hypercalcemia of malignancy. Proc Natl Acad Sci USA 1988;85:597-601.

6 Horiuchi N, Caulfield MA, Fisher JE, et al. Similarity of synthetic peptide from human tumor to parathyroid hormone in vivo and in vitro. Science 1987;238:1566-8.

7 Kemp BE, Moseley JM, Rodda CP, et al. Parathyroid hormone-related protein of malignancy; active synthetic fragments. Science 1987;238:1568-70.

8 Thorikay H, Kramer S, Reynolds FH, et al. Synthesis of a gene encoding parathyroid hormone-like protein (1-141): purification and biological characterisation of the expressed protein. Endocrinprotein $(1-141)$ : purice

9 Kukreja SC, Shevrin DA, Wimbiscus S, et al. Antibodies to parathyroid hormone-related protein lower serum calcium in athymic mouse models of malignancy-associated hypercalcemia due to lower serum calcium in athymic mouse models

10 Gowen M, Wood DW, Ihrie EJ, McGuire MKB, Russell GG. An interleukin-1 like factor stimulates bone resorption in vitro. Nature 1983;306:378-80.

11 Ibbotson KJ, Twardzik DR, D'Souza SM, Hargreaves WR, Todaro GJ, Mundy GR. Synthetic transforming growth factor alpha stimulates bone resorption in vitro. Science 1985;228: 1007-9.

12 D'Souza SM, Ibbotson KJ, Smith DD, Mundy GR. Production of a macromolecular bone resorbing factor by the hypercalcemic variant of the Walker rat carcinosarcoma. Endocrinology 1984;115:1746-52.

13 Tashjian AH Jr, Levine L. Epidermal growth factor stimulates prostaglandin production and bone resorption in cultured mouse calvaria. Biochem Biophys Res Commun 1978;85:966-75.

14 Bertolini DR, Medwin GE, Bringman TS, Smith DD, Mundy GR. Stimulation of bone resorption and inhibition of bone formation in vitro by human tissue necrosis factor. Nature 1986;319:516-8.

15 Tashiian $\mathrm{AH} \mathrm{Jr}, \mathrm{Hohmann} \mathrm{EL}$ Antoniades $\mathrm{HN}$, Levine L. Platelet derived growth factor Thimulases bone resorption 111:118-24.

16 Klein DC, Raisz LG. Prostaglandins; stimulation of bone resorption in tissue culture. Endocrinology 1970;86:1436-40.

17 Loveridge N, Kent GN, Heath DA, Jones EL. Parathyroid hormone-like bioactivity in a patient with severe osteitis fibrosa cystica due to malignancy: renotrophic actions of a tumour extract as

18 Brown RC, Aston JP, Weeks I, Woodhead JS. Circulating intact parathyroid hormone measured by a two-site immunochemiluminometric assay. F Clin Endocrinol Metab 1987;65:407-14.

19 Thalassinos NC, Joplin GF. Failure of corticosteroid therapy to correct the hypercalcaemia of malignant disease. Lancet 1970;ii:537-9.

20 Percival RC, Yates AJ, Gray RE, Neal FE, Forrest ARW, Kamis JA. Role of glucocorticoids in management of malignant hypercalcaemia. BrMed f 1984;289:287.

21 Hosking DJ, Gilson D. Comparison of the renal and skeletal actions of calcitonin in the treatment of severe hypercalcaemia of malignancy $Q \mathcal{J}$ Med 1984;211:359-69.

22 Hasling $C$, Charles $P$, Mosekilde L. Etidronate disodium in the management of malignancy related hypercalcemia. $A m$ F Med 1987;82(suppl 214):51-4.

23 Mundy GR, Wilkinson R, Heath DA. Comparative study of available medical therapy for hypercalcemia of malignancy. Am f Med 1983;74:421-32.

\title{
Difficulties raised by insurance medical reports
}

\section{Make sure patients have given consent and avoid conjecture}

Doctors have been helping insurance companies and patients by completing "personal medical attendants' reports" for insurance policies since the last century. This process has worked well-so long as safeguards recommended in the BMA's Handbook of Medical Ethics ${ }^{1}$ are followed-but now AIDS is presenting new problems. Insurance companies are anxious to pick up on anybody who might be infected with HIV, and patients are disturbed by their doctors being asked very personal questions about them.

In the past doctors have acted in the best interest of patients even when reporting adverse features of their medical histories - because if an incorrect statement or relevant fact is overlooked then insurers may reject a claim and the patient may forfeit paid premiums. Now, because of AIDS, insurance companies have included questions in the personal medical attendants' reports about possible contact with sexually transmitted diseases, which are upsetting both doctors and patients. And the Medical Reports Act, which came into force at the beginning of the year, will mean that patients have access to what doctors say about them in their medical reports.

A study from Hampshire reported on p 1495 showed that 
half of more than 200 patients on whom doctors were asked to complete personal medical attendants' reports could not recall having given their permission. A third objected to questions on sexual habits, and over half expected their doctors to withhold sensitive information. This report should help general practitioners when preparing reports for insurance companies, and it suggests that they should make sure that their patients know that they are completing them: they might also discuss with the patients whether they are happy for certain information to be released.

Insurance companies should consider carefully the questions they ask so that doctors' relationships with their patients are not harmed. For instance, a question such as "Is there anything about the patient's lifestyle that makes it likely that the patient will get a sexually transmitted disease?" puts an improper strain on the professional relationship. Such questions should be directed at the patient; doctors should be expected to report medical fact not conjecture.

The relation between insurance companies and the proposer's general practitioner is important to nurture as together they may help the proposer to achieve a just contract. Great care and goodwill are needed in negotiating between the two groups to ensure a happy relationship and to reassure patients that their doctors will disclose only medical facts for which they have given informed consent.

JOHN D BEALE

General Practitioner,

Ramsgate, Kent CT11 9NB

1 British Medical Association. Handbook of medical ethics. London: BMA, 1986.

\section{Causes of cataract}

\section{Age, sugars, and probably ultraviolet $B$ radiation}

Around the world about 17 million people are blind because of cataract. ${ }^{1}$ Although cataract is treatable by operation, increasingly the resources of poor countries are outstripped by the growing demand. ${ }^{2}$ In rich countries an increasing proportion of resources is consumed by treating cataracts. In England and Wales operations for cataracts increased by almost two thirds in the decade up to $1985,{ }^{3}$ and there was an increase of $177 \%$ in the decade before 1976 in the United States, ${ }^{4}$ where one million cataract operations were carried out in 1987. Clearly, prevention of cataract should be emphasised, but unfortunately the cause of the commonest form of cataract - that related to aging - remains an enigma.

There are many causes of cataract, which is the common response to a physical, mechanical, or chemical insult. ${ }^{5}$ The transparency of the lens of the eye depends on a unique arrangement of tightly packed fibres, which in turn rely on a certain protein structure; and the lens is isolated in its special environment by a capsule and epithelium. Hence damage to the capsule, epithelium, or the constituent fibres of the lens may all lead to the formation of a cataract, and the injury may be cumulative over many years.

The most studied cataracts are those that may be caused by high concentrations of various sugars. ${ }^{6}$ The best understood form of cataract occurs in galactosaemia, which results from a lack of the enzyme galactose-1-phosphate uridyltransferase or galactokinase. The galactose that accumulates is converted to galactitol in the presence of aldose reductase and leads to increased osmotic pressure and hydration as galactitol does not diffuse out of the capsule. An aldose reductase inhibitor would prevent the conversion of galactose to galactitol and has been shown to prevent and reverse early cataract when instilled topically into the eyes of galactosaemic rats.

In diabetics under 60 the prevalence of cataract is three or four times that in the normal population, ${ }^{8}$ and the cataracts may develop similarly to those in patients with galactosaemia - yet whereas the evidence in animal studies is suggestive the case in humans is less convincing. ${ }^{9}$ An alternative hypothesis is that non-enzymatic glycosylation occurs ${ }^{10}$ : this explains both the increased pigmentation and protein aggregation in the lens and accords with the finding of a blood glucose concentration that is higher in patients with cataracts than in controls. ${ }^{11}$

Much more important than the effect of sugars in causing cataract is the potential effect of electromagnetic radiation. The damaging effects on the lens of ionising, microwave, and infrared radiation are well known, ${ }^{12}$ but hitherto the effects of ultraviolet radiation from the sun have been uncertain. Most of the ultraviolet radiation is filtered out by the cornea, and only wavelengths of $295 \mathrm{~nm}$ or greater pass through. But the lens absorbs nearly all the ultraviolet from $295 \mathrm{~nm}$ to $400 \mathrm{~nm}$, and the high prevalence of cataract in countries with hot climates has meant that the harmful effect of ultraviolet radiation has long been suspected. ${ }^{13}$

Some epidemiological data already support the hypothesis that absorbing ultraviolet radiation from sunlight is an important risk factor in forming cataracts. ${ }^{14}$ The hypothesis fits the observations of increased yellowing of the lens nucleus with aging ${ }^{12}$ and that exposure to ultraviolet radiation leads to the formation of chromophores from proteins containing tryptophan, thus increasing the potential of the nucleus to absorb more radiation. ${ }^{16}$ The precise mechanism is still disputed but may depend on the oxidation of free radical scavengers setting in train reactions that lead to protein aggregation. ${ }^{17}$

Although this hypothesis fits the changes that occur in the nucleus, it does not match the observation that age related cataracts commonly affect the outer cortex. Furthermore, epidemiological data from India suggested that the prevalence of cataract was higher in the cloudier plains of Punjab than in the sunnier hills of the Himalayas. ${ }^{18}$ A later study repeated in the same region found a correlation between cataract and the concomitants of poverty, notably poor nutrition and hygiene. ${ }^{19}$ In such cases a powerful risk factor may be dehydration from serious diarrhoea, which may increase blood urea concentrations and thus make cyanate more available for carbamylation of lens protein. ${ }^{20}$ Diarrhoea was an important risk factor in a study in Madhya Pradesh ${ }^{21}$ and (somewhat surprisingly) in Oxford..$^{22}$

More recently a tightly controlled study on watermen in the Chesapeake Bay showed correlation between cataract and prolonged exposure to sunlight ${ }^{23}$; exposure to ultraviolet $\mathrm{B}$ radiation $(295-320 \mathrm{~nm})$ was important whereas that to ultraviolet A radiation (320-400 nm) was fairly unimportant, and the positive relation was with cortical rather than nuclear cataract.

Although more evidence is accumulating to support the 